\title{
"Por trás da máscara da loucura": cenários e desafios da assistência à pessoa com esquizofrenia no âmbito da Atenção Básica
}

\author{
Ailton Pereira da Silva ${ }^{\text {Orcid, I, } \star ~ E l l a n y ~ G u r g e l ~ C o s m e ~ d o ~ N a s c i m e n t o ~}{ }^{\text {Orcid, I }}$ \\ João Mário Pessoa Júnior, Orcid, II Juce Ally Lopes de Melo ${ }^{\text {Orcid I }}$ \\ ${ }^{I}$ Universidade do Estado do Rio Grande do Norte, Mossoró, RN, Brasil \\ II Universidade Federal Rural do Semi-Árido, Mossoró, RN, Brasil
}

\begin{abstract}
Resumo
Objetivo: Analisar os cenários e desafios enfrentados pelos profissionais de saúde na assistência às pessoas com esquizofrenia na Atenção Básica. Método: Pesquisa qualitativa, de caráter descritivo-exploratório, realizada junto a médicos e enfermeiros que atuam na Atenção Básica do municipio de Pau dos Ferros, Rio Grande do Norte. Utilizaram-se entrevistas semiestruturadas com dez profissionais; as falas foram analisadas em quatro categorias, através da Análise de Conteúdo. Resultado: constatou-se que a assistência prestada à pessoa com esquizofrenia não consegue identificar e atender às suas reais necessidades e que as propostas das políticas públicas de saúde mental se distanciam da realidade, pois as ações na atenção básica se limitam à orientação da medicação e ao encaminhamento para o serviço de referência, o que contraria o princípio da integralidade da assistência, sendo necessárias aos profissionais da atenção básica maior autonomia e participação nesse processo. Para tanto, se faz imprescindivel o uso de um trabalho integrado entre os profissionais, a adoção de um modelo de contrarreferência e a diversificação dos instrumentos de intervenção em saúde.
\end{abstract}

Palavras-chave: assistência; sofrimento mental; esquizofrenia; atenção básica.

\section{"Behind the Mask of Madness": scenarios and challenges of assistance to individuals with schizophrenia in primary care}

\begin{abstract}
Objective: To analyze the scenarios and challenges faced by health professionals in the care of people with schizophrenia in Primary Care. Method: Qualitative research, descriptive and exploratory, performed with physicians and nurses who work in Primary Care in the city of Pau dos Ferros, Rio Grande do Norte. We used semi-structured interviews with ten professionals, the lines were analyzed in four categories, through Content Analysis. Result: was found that the assistance provided to the person with schizophrenia can not identify and meet their real needs and that the proposals of the public policies of mental health are distanced from the reality, since the actions in the basic attention are limited to the orientation of the medication and the referral service, which is contrary to the principle of integral care, and it is necessary for the primary care professionals to have greater autonomy and participation in this process. Therefore, it is essential to use integrated work among professionals, the adoption of a counter-reference model and the diversification of health intervention instruments.
\end{abstract}

Keywords: assistance; mental suffering; schizophrenia; basic attention.

\section{Introdução}

Desde os primórdios, a sociedade humana difunde padrões e conceitos que, na maioria das vezes, devem ser adotados por seus membros como requisitos de inclusão dos indivíduos no sistema que coordena. Na medida em que o indivíduo não se adéqua aos padrões ou expectativas impostos pelo meio social, seja de comportamento, pensamentos, atitudes ou outros, desencadeia-se o processo de exclusão, reforçando-se preconceitos existentes e diferenças expressas na singularidade de cada um (SILVEIRA, L.; BRAGA, 2005). Dentre os grupos historicamente excluídos desse sistema, têm-se as pessoas com transtornos mentais e comportamentais que, por vezes, foram negligenciadas pelas políticas públicas de saúde, mediante abordagens e práticas marcadas pelo isolamento social.

\footnotetext{
^Endereço para correspondência: Universidade do Estado do Rio Grande do Norte, Faculdade de Ciências da Saúde. Rua Atirador Miguel Antônio da Silva Neto, s/n. Aeroporto - Mossoró, RN - Brasil. CEP: 59607360. E-mails: ailtopereira@yahoo.com.br, ellanygurgel@hotmail.com,joaomariopessoa@gmail. com, juceally@hotmail.com
}

Sabe-se que, no campo da atenção às pessoas com transtornos mentais, a rotulação de louco e a exclusão ao longo dos anos trouxeram repercussões negativas a este grupo considerado incapaz de desenvolver hábitos e atitudes sociáveis. (CANABRAVA et al., 2010). Na contramão dessa lógica, a Reforma Psiquiátrica (RP) - movimento internacional de lutas por mudanças na assistência psiquiátrica, a exemplo de países como Itália, França e Inglaterra, buscou romper com o modelo manicomial e asilar que segregava as pessoas com transtornos mentais do convívio familiar. Fortalece-se a ideia de tratamento humanitário e sem confinamento, que estimula sobremaneira a reinserção social do indivíduo na comunidade.

Inspirado nos ideais da RP, o Brasil (2001), a partir da Lei Federal 10.216/01 e Política Nacional de Saúde Mental, avança na perspectiva da adoção do modelo atenção psicossocial, com bases comunitárias, instituindo novos serviços e estratégias em saúde mental para acompanhamento das pessoas com transtornos mentais e suas famílias (BRASIL, 2015). Criam-se, entre outros, os Centros de Atenção Psicossocial (CAPS), o Serviço Residencial Terapêutico 
(SRT), Ambulatórios de Saúde Mental, além de estratégias como Geração de Renda Economia Solidária, Leitos de Saúde Mental em hospitais gerais e saúde mental na Atenção Básica, que, em conjunto, atuam de maneira articulada compondo a Rede de Atenção Psicossocial (RAPS).

Entre os desafios, destaca-se o fortalecimento da saúde mental na Atenção Básica (AB), estruturada a partir da Estratégia Saúde da Família, (ESF) que carece de maiores investimentos financeiros e sofre com a falta de recursos humanos qualificados para se ampliarem as ações e os atendimentos às demandas nesse campo. Em municípios que ainda não dispõem de uma RAPS ou mesmo de serviços especializados instalados, como o CAPS, a ESF concentra importante papel na assistência psiquiátrica (PESSOA JÚNIOR et al., 2016).

No contexto dos transtornos mentais complexos, de múltiplas causas e, na maioria das vezes, diagnosticada em fase mais avançada, a esquizofrenia constitui um problema de saúde pública a ser enfrentado, especialmente no âmbito dos serviços que compõem a $\mathrm{AB}$. Dadas as barreiras de convívio social, dificuldades das famílias em lidar com os sintomas na fase aguda da doença e a falta de acolhimento ou atendimento qualificado, entende-se a necessidade de se implementar ações e estratégias de cuidado em saúde mental pelas equipes da ESF voltadas às pessoas com esquizofrenia.

Preconiza-se o acompanhamento integral, englobando os diversos serviços e dispositivos que compõem a RAPS, articulando a ESF e o próprio no cuidado integral e longitudinal não apenas à pessoa com transtorno mental como também à família (PALMEIRA; GERALDES; BEZERRA, 2009). Reconhece-se, portanto, o papel social da AB na RAPS na promoção da saúde mental e no desenvolvimento de ações articuladas a partir da interdisciplinaridade e da intersetorialidade.

Visto o papel relevante da ESF no processo de inclusão social e na promoção do bem-estar da população em geral, almeja-se que "as ações de saúde mental na atenção básica devem obedecer ao modelo de redes de cuidado, de base territorial e atuação transversal com outras políticas específicas, e que busquem o estabelecimento de vínculos e acolhimento" (BRASIL, 2004, p. 03). Cabe aos profissionais da atenção básica propiciar cuidados em saúde mental voltados às pessoas com esquizofrenia, mesmo que estas estejam sob os cuidados de outros profissionais (FERREIRA, G., 2006).

Assim, o presente estudo tem como objetivo analisar os cenários e desafios enfrentados pelos profissionais de saúde na assistência às pessoas com esquizofrenia na Atenção Básica.

\section{Método}

Pesquisa de natureza exploratória e descritiva, abordagem qualitativa realizada no município de Pau dos Ferros, Rio Grande do Norte, junto aos profissionais de saúde (médicos e enfermeiros) que atuam na Estratégia Saúde da Família (ESF). A escolha dos participantes se

Fractal, Rev. Psicol., v. 31 - n. 1, p. 2-10, 2019 deu por serem profissionais com contato direto com a população, além de disporem de formação específica para realizar abordagens aos usuários em questão.

Entre as oito Unidades Básicas de Saúde houve a participação de dez profissionais, sendo cinco enfermeiros e cinco médicos. Os critérios de inclusão estabelecidos foram: ser profissional enfermeiro ou médico atuante na ESF devidamente cadastrado na Secretaria Municipal; trabalhar na ESF há pelo menos seis meses. E os critérios de exclusão: estar de férias ou de licença do serviço em que atua no momento da coleta de dados.

O roteiro norteador da entrevista foi composto por questões que contemplavam as concepções sobre a esquizofrenia e seus efeitos, as políticas públicas de saúde mental e o papel da ESF na promoção da saúde mental. Durante o processo de elaboração do roteiro, foi considerada a relação entre teoria e prática, com a finalidade de tornar o entendimento das questões viável.

A realização das entrevistas aconteceu nos locais de trabalho dos profissionais, nas respectivas UBS, após a assinatura do Termo de Consentimento Livre e Esclarecido (TCLE). Os dados foram coletados e armazenados por meio da gravação com minigravador digital, posteriormente transcritos.

As fases de análise do conteúdo incluíram inicialmente a transcrição das respostas encontradas, a organização do material coletado e realização da leitura, para obter uma categorização dos dados obtidos, para atingir uma representação do conteúdo ou de sua expressão. Após ser concluída a fase da coleta de dados, foram realizadas a análise e a categorização das respostas obtidas nas entrevistas, de modo a avaliar a presença de semelhanças e diferenças nos diferentes discursos registrados (MINAYO, 2002).

A partir da interpretação das falas, foram geradas quatro categorias temáticas de discussão: I) Conceituações dos profissionais acerca da Esquizofrenia; II) Assistência à pessoa com esquizofrenia na Atenção Básica - da ideal à real; III) Entraves para assistência em saúde à pessoa com esquizofrenia; IV) Possibilidades para melhoria do trabalho em saúde mental.

O projeto foi aprovado pelo Comitê de Ética em Pesquisa (CEP) da Universidade do Estado do Rio Grande do Norte (UERN), em 15 de Julho de 2011, n CAAE (SISNEP) 0003.0.428.428-11, protocolo (CEP) No $\mathrm{N}^{\circ}$ 007/11.

\section{Resultados e discussões}

\section{Conceituações dos profissionais acerca da Esquizofrenia}

Representa as conceituações sobre esquizofrenia e os seus efeitos na vida social da pessoa com transtorno mental. O primeiro conceito que emergiu nas falas foi o de "doença incapacitante", com sequelas não apenas psíquicas, mas também no convívio social. Os depoimentos abaixo expõem o receio que os profissionais da atenção básica têm em lidar com usuários com esquizofrenia, sobretudo evidencia atitude de preconceito e medo adotada pela maioria da população:

É um mal que, infelizmente, limita, sequela o cidadão na sociedade e o deixa inválido. [...] é um problema 
também que além de sequelar a pessoa, também a torna vítima de preconceito da sociedade (profissional de saúde E).

[...] Eu tenho medo de esquizofrênico! [...] Já tive a oportunidade de trabalhar, de fazer visitas a pacientes esquizofrênicos e eu tinha muito medo, sempre ficava na retaguarda porque eu nunca sabia qual reação ele teria. Infelizmente é isso que eu penso (profissional de saúde F).

O segundo conceito observado foi o de "doença que altera o comportamento humano". Na maioria das falas há ênfase na descrição de sinais e sintomas da doença como forma de exporem o seu entendimento sobre a esquizofrenia. Por outro lado, demonstram desconhecimento ou uma definição reducionista sobre as causas e os sintomas da doença.

A esquizofrenia é um problema muito grave porque as pessoas aparentam ter um comportamento e mudam de comportamento muito rápido. Pra mim não são pessoas confiáveis! (profissional de saúde F).

É uma pessoa que já deve ter passado por problemas de comportamento, gerados por $N$ causas e que ela não pode sair (profissional de saúde $\mathrm{H}$ ).

[...] a gente vê que é algo muito triste porque vê que a pessoa, ela experimenta de momentos de lucidez a momentos em que ela está com as ideias sem coordenação (profissional de saúde $\mathrm{H}$ ).

O terceiro conceito aponta para esquizofrenia como doença que requer diagnóstico e tratamento adequado:

[...] o esquizofrênico depois do primeiro surto que ele tem de esquizofrenia e ele recebe diagnóstico, se faz um tratamento, o tratamento vai equilibrar os neurotransmissores dele e ele pode passar meses, anos ou décadas sem ter recaídas e viver bem [...] Mas, infelizmente, se o diagnóstico não é dado rapidamente, o tratamento não é feito da maneira correta e o indivíduo começa a ter uma piora da qualidade de vida social muito grande que marca negativamente a história dele (profissional de saúde D).

O que se caracteriza como um problema que tem que ser tratado (profissional de saúde E).

Mesmo com os avanços advindos com a terapêutica medicamentosa e o novo paradigma da reabilitação psicossocial, que estimula o processo de convívio social da pessoa com transtorno mental, os profissionais de saúde demonstram desconhecimento ou falta de habilidade em lidar com pessoas com esquizofrenia e seus familiares. Tal concepção, em parte, remete à concepção higienista de loucura de outrora. Soma-se a isso o fato de este pensamento contribuir para o isolamento desse público, fato que se contrapõe à assistência em saúde mental e ao processo de reabilitação psicossocial (JARDIM; DIMENSTEIN, 2007).

Entende-se que a rotulação de "louco" e "incapaz" se torna grande empecilho à manutenção da saúde mental equilibrada por parte das pessoas com esquizofrenia e suas famílias. O background sociocultural, ou seja, a cultura, juntamente com fatores socioeconômicos, pode influenciar nas manifestações do estigma relacionado a indivíduos com esquizofrenia (HENGARTNER et al., 2012).

Observa-se em algumas falas uma visão ampliada do conceito de esquizofrenia, enfatizando a relação entre o diagnóstico e a terapêutica. No geral, os depoimentos denotam uma concepção de esquizofrenia como uma doença do grupo de transtornos psiquiátricos que traz modificações profundas não só para a pessoa, desde o momento do diagnóstico, mas também para o seu meio familiar e social.

Sabe-se que a esquizofrenia se apresenta como um problema de saúde pública, de evolução crônica e marcada pela desorganização dos processos mentais e pelo forte estigma social. Na maioria dos casos, a idade de início do transtorno varia entre 15 e 20 anos para os homens e entre 20 e 25 anos para as mulheres. Atualmente, o acompanhamento multiprofissional e adesão adequada ao tratamento possibilitam uma melhoria no desempenho das atividades diárias e maior qualidade de vida (HANSEN et al., 2014).

Desde o processo de formação dos profissionais de saúde, em nível de graduação, observam-se atitudes preconceituosas em relação aos transtornos mentais, de modo que esses estigmas podem influenciar no tratamento ofertado e na interação com os pacientes de vários segmentos da comunidade, pois fortalece a crença de que os pacientes psiquiátricos são imprevisíveis e exibem comportamento violento, o que contribui para o distanciamento social e o aumento do estigma (FERREIRA, F. et al., 2015).

Destacamos que os profissionais de saúde devem ter consciência de que suas atitudes podem gerar maior impacto na sociedade do que as atitudes da população em geral. Portanto, é preciso precaução para não se gerar uma ideia errônea acerca da doença que possa contribuir para aumentar a estigmatização do paciente e prejudicar a interação deste com vários segmentos da sociedade (FERREIRA, F. et al., 2015). Nesse sentido, faz-se necessário abandonar os mitos e preconceitos, especialmente por parte dos profissionais de saúde, com vistas a promover uma assistência em saúde mental ética e de qualidade (ASSOCIAÇÃO BRASILEIRA DE PSIQUIATRIA [ABP], 2014).

Deve-se ressaltar que, devido a questões culturais, o esquizofrênico acaba por ser excluído da sociedade pela família, por ele mesmo e pelas outras pessoas, e isso acaba se constituindo como um fator agravante do quadro clínico do paciente, já que a evolução desta patologia está atrelada ao convívio social. Torna-se fundamental a luta contra o estigma; para tanto faz-se necessária a educação para a saúde mental tanto para os familiares como para a sociedade em geral (SHIRAKAWA, 2000).

\section{Assistência à pessoa com esquizofrenia na Atenção Básica-da ideal à real}

A demonstração acerca da percepção da assistência à pessoa com esquizofrenia na Atenção Básica, representada nas falas, inicia-se elencando as principais necessidades das pessoas com essa doença, para um melhor atendimento em saúde mental nesses serviços. 
O primeiro item a ser identificado pelos profissionais de saúde foi o atendimento multiprofissional:

[...] acho que o portador de esquizofrenia ele deve ter uma equipe multidisciplinar para acompanhá-lo, não só da unidade básica, mas a parte de psicólogo, de assistente social, de médico, de nutricionista. Tem que ter todo esse aparato para poder tá trabalhando com ele [...] (profissional de saúde I).

[...] São pessoas que precisam de um acompanhamento tanto por parte da equipe quanto de um acompanhamento especializado (profissional de saúde G).

A maior necessidade é o acompanhamento psiquiátrico, tanto o acompanhamento com o profissional como o acompanhamento de psicoterapia [...] (profissional de saúde D).

Apesar de reconhecerem que os usuários com esquizofrenia necessitam de um atendimento multidisciplinar, os participantes do estudo não destacam como seria a atuação dos outros profissionais no âmbito da equipe mínima de saúde de família (enfermeiro, médico, técnico de enfermagem e agentes comunitários de saúde). Observa-se a transferência de responsabilidade do profissional da atenção básica na assistência à pessoa com esquizofrenia, por vezes delegada aos profissionais do serviço especializado (CAPS, ambulatório de saúde mental, etc.) ou mesmo o Núcleo de Apoio à Saúde da Família (NASF), que engloba em sua equipe médico, psiquiatra, psicólogos, entre outros.

A atuação de profissionais de saúde especialistas e específicos para casos de saúde mental não exclui as ações a serem desenvolvidas pelos profissionais generalistas da atenção básica, de modo a constituir um sistema de referência e contrarreferência que, de maneira ampliada e articulada, constitui a RAPS. A organização dos serviços ou das ações de saúde mental na atenção básica pressupõe priorizar as necessidades de saúde dos usuários e famílias como eixo central do cuidado (SILVEIRA, D., 2003)

Outro item destacado pelos profissionais foi a ênfase na terapêutica medicamentosa, como se observa nos depoimentos a seguir:

[...] É necessário um acompanhamento continuado da medicação que fazem uso, é necessário ver também como está a sua readaptação ao convívio em sociedade e também ver como está o meio que cerca ele, se a família está preparada para lidar com essa situação, porque têm muitos casos em que o problema já começa de casa [...] (profissional de saúde J).

O que é feito no PSF não é nem o acompanhamento da medicação, mas talvez a troca de receitas para que o paciente ele tenha acesso à sua medicação [...] (profissional de saúde H).

Vê-se que os profissionais concebem como maior necessidade da pessoa com esquizofrenia o acesso aos medicamentos. Na realidade dos serviços da atenção básica, se verifica que o usuário ou a família procurava o serviço de saúde apenas para ter acesso à receita médica e, por consequência, à medicação psicotrópica, sendo que alguns até enfatizaram que essa seria a maior necessidade, a qual era atendida. Todavia, desvinculada de outras intervenções, ela não poderá ocasionar a melhora significativa do quadro clínico-social do paciente.
Neste contexto, ao citarem o tratamento medicamentoso, os profissionais acabam reforçando o modelo biomédico da contenção farmacológica dos sintomas, pelo qual se fortalece a crença de que os pacientes indesejáveis devem ser mais medicados e que devem tolerar mais efeitos colaterais a longo prazo (LOCH et al., 2011). Negligenciam-se, assim, outros aspectos terapêuticos fundamentais que, em conjunto, podem constituir uma assistência integral, envolvendo aspectos não medicamentosos, como a autonomia, o trabalho ou alguma atividade produtiva, a terapia ocupacional, a terapia familiar e a psicoterapia individual. No imaginário social, a crença de que a medicação cura e afasta os delírios, devolvendo tranquilidade ao paciente e à família, torna-se, por vezes, um mito ou uma ilusão. (PALMEIRA; GERALDES; BEZERRA, 2009). Destarte, muitos desses casos que se encontram em regime ambulatorial são insuficientemente tratados e ficam desestabilizados, contribuindo para uma impressão negativa (LOCH et al., 2011).

No que se refere à participação da família no tratamento em saúde mental realizado na atenção básica, os profissionais dizem o seguinte:

[...] Eu acho que a maior a necessidade é principalmente atenção e outra necessidade também eu vejo a questão da família, de tentar melhorar o quadro dessa pessoa, de tentar buscar alternativas [...] (profissional de saúde F).

[...] trabalhar a família de modo que permita que esse pessoal esteja realmente fazendo uso do medicamento (profissional de saúde $\mathrm{G})$.

Percebe-se, entre as necessidades mencionadas pelos profissionais, o papel central da família na adesão e manutenção do tratamento, repercutindo positivamente no processo de reinserção social das pessoas com esquizofrenia, tendo em vista que, em grande parte do tempo, estas estão em convívio direto no seio familiar. Da mesma forma, enfatizaram a necessidade de desmistificar os preconceitos ainda existentes em relação a estas pessoas, para que possam ser acolhidas no meio social.

Entretanto, na maioria das vezes, falta maior preparo ou mesmo conhecimento acerca da doença mental enfrentada. Tal realidade pode ser melhorada com o apoio direto dos profissionais da ESF, seja orientando sobre o tratamento ou mesmo acompanhando as angústias vivenciadas, de modo a buscar conjuntamente estratégias de enfrentamento.

Sobre os cenários da assistência em saúde mental à pessoa com esquizofrenia no âmbito da atenção básica, especificamente a realidade como ela é, os participantes do estudo destacaram as principais ações, a saber: a visita domiciliar e o encaminhamento para serviços especializados. A visita domiciliar se configura como importante instrumento na abordagem da pessoa com esquizofrenia pelos profissionais, fato que justifica a predominância desta ação nas falas participantes:

$\mathrm{Na}$ verdade meu envolvimento é pequeno demais. Como falei, eu tenho medo. A gente não tem esse envolvimento! [...] O que a gente faz é uma visita, é uma coisa mais assim

[...] Tentando referenciar para um cuidado especifico. Mas a gente nunca traz essas pessoas pra cá, até mesmo porque 
elas não vêm também. Não existe esse envolvimento (profissional de saúde F).

Os usuários esquizofrênicos geralmente são pessoas que devido a uma própria característica da doença acabam se isolando e tornam-se reclusos da sociedade. Neste sentido, o contexto de vida, o domicílio e os aspectos socioculturais podem ser reveladores para o maior entendimento do processo saúde-doença mental e trazer novos olhares para a conduta clínica dos profissionais.

Embora, como relatado pelos profissionais, não seja tão frequente devido às outras demandas, a visita domiciliar se configura como principal atividade voltada às pessoas com esquizofrenia, conforme os relatos:

[...] a visita domiciliar é mais pelo agente, só fazemos uma visita quando o agente ele diz que há necessidade, porque a gente sabe que a demanda é muito grande. Mas quando o paciente vem até a gente, nós tentamos ouvir esse paciente e tem a família também (profissional de saúde G).

Apenas a visita domiciliar. O agente de saúde vem, chama, a gente faz a visita, leva o médico, passa por aquela parte de suplemento, faz o acompanhamento da medicação controlada. Não existe nada fora isso! (profissional de saúde H).

O que a gente faz aqui é uma visita, até mesmo porque como enfermeira eu não posso prescrever e essa assistência que a gente sabe que é necessária depende muito do médico e não podemos obrigar nossos colegas a fazerem o que não querem (profissional de saúde $\mathrm{H}$ ).

[...] Se for preciso a gente faz uma visita quando o agente de saúde identifica o caso e nos comunica (profissional de saúde C).

Mesmo considerando a relevância da visita domiciliar no trabalho da atenção básica, a ferramenta ainda é utilizada de forma incipiente. Cabe reforçar a necessidade de sistematizar e organizar melhor tal instrumento, considerando o contexto de saúde mental, tornando-a assim mais efetiva. Desse modo, deve-se romper a ideia de visita domiciliar como uma atividade rotineira ou pontual a ser realizada pela equipe, mas tornar esse momento um potente encontro de acolhimento, de orientações e de fortalecimento do vínculo entre família e serviço.

A visita domiciliar da equipe da atenção básica em relação ao paciente com transtornos mentais compreende acolher, diagnosticar e tratar os casos de sofrimento mental inespecífico, bem como propiciar atenção integral à família. De modo que, considerando a diversidade de casos, torna-se importante a formação em saúde mental, treinamentos ou atualizações, para minimizar as dificuldades em desenvolver ações nesta área, bem como para acompanhar mudanças propostas nas diretrizes da Reforma Psiquiátrica Brasileira (SILVA, 2011).

Foram destacados, ainda, entre as ações realizadas, a prescrição de medicamentos e os encaminhamentos aos serviços especializados:

$\mathrm{Na}$ prescrição dos medicamentos, no encaminhamento para profissionais especializados [...] A gente prescreve os medicamentos. Mas nem sempre acompanha o paciente, ele mesmo se esquiva e a família não procura o serviço (profissional de saúde A).
O meu papel como enfermeiro está na questão de proporcionar o bem-estar a estes pacientes. Tentar fazer algo com que eles possam ter uma melhor qualidade de vida [...] Mas, [...] como a gente tem o CAPS como referência aqui, então a gente vê muito a questão do encaminhamento, de 'vê' como é que 'tá', de tentar sempre conversar com o pessoal por causa da questão do medicamento (profissional de saúde G).

[...] Encaminhamos para o CAPS e deixamos esse paciente sobre a responsabilidade do CAPS. A gente aqui na verdade não prescreve nada não, a gente apenas faz um acompanhamento da medicação que é prescrita lá no CAPS, o que a gente faz aqui é 'dá 'alguma orientação quando há a troca da medicação, por exemplo (profissional de saúde C).

A questão do encaminhamento exprime para muitos uma ação efetiva no cuidado com a saúde da pessoa em sofrimento mental. Entretanto, pode demonstrar eximir-se da responsabilidade. Segundo Franco (2003), encaminhamentos sem esgotamento das possibilidades diagnósticas na rede básica, informações necessárias sobre o quadro mórbido, revelam uma atuação com falta de solidariedade com o serviço e de responsabilização no cuidado ao usuário.

Um depoimento chamou atenção, pelo modo de reconhecer também as falhas existentes no trabalho que a equipe da Estratégia Saúde da Família desenvolve. Menciona a necessidade de mudanças nesse trabalho, enfocando também a questão do trabalho que é desenvolvido de forma desarticulada entre diferentes profissionais.

Na verdade o que a gente faz aqui é pouco. Logo porque tem o CAPS que é aqui perto e se é dos usuários procurarem a unidade de saúde eles procuram o CAPS. Mas faço o que posso se for preciso, encaminho pro serviço social, pra médica aqui da unidade ou até mesmo para o CAPS (profissional de saúde $\mathrm{H}$ ).

Furtado (FURTADO; CAMPOS, 2005) destaca que, do ponto de vista dos princípios do SUS, se torna muito importante a existência nos municípios de um serviço de referência em saúde mental como o CAPS para atender a demanda de pacientes. Entretanto, o funcionamento deste serviço deve seguir as bases de apoio matricial, onde são referenciados os casos provenientes da atenção básica que, após fazer esse encaminhamento, continua a acompanhar o tratamento do usuário. A proposta dos CAPS objetiva o acompanhamento da clientela considerada mais comprometida em termos psicossociais, conforme a gravidade do quadro clínico ou a cronicidade pelos longos anos de internação (SILVEIRA, D., 2003).

Afinal, verifica-se que a maior resolutividade da assistência prestada pelas Unidades Básicas de Saúde poderá reduzir as necessidades das consultas especializadas e exames, reservando os recursos públicos para garantir os procedimentos realmente necessários (FRANCO, 2003).

\section{Entraves para assistência em saúde à pessoa com esquizofrenia}

Destacam-se os principais entraves e desafios enfrentados pelos profissionais de saúde na assistência à pessoa com esquizofrenia. Três aspectos emergiram nos depoimentos: a falta de envolvimento e participação da família 
no tratamento, a ausência de ações e atividades voltadas às pessoas com esquizofrenia e ausência de ações e atividades voltadas às pessoas com esquizofrenia.

Entre as dificuldades na execução de ações em saúde mental, tem-se a falta de envolvimento e participação da família em lidar com o ente com doença mental, o que acaba por dificultar a adesão ao tratamento.

Os problemas são muitos! A começar pela família que não aceita o problema e tenta escondê-lo, a sociedade que exclui o portador da patologia. De modo geral, a impossibilidade de cumprir o que propõem as políticas públicas de saúde mental, uma vez que não há um serviço de referência consistente, como é o caso da nossa realidade, em que há um CAPS para vários municípios, um psiquiatra para todos estes municípios (profissional de saúde A).

A família não participa! Na maioria das vezes eles não entendem a dimensão do problema ou não querem aceitar e isso atrapalha e muito o paciente (profissional de saúde A).

Muitas vezes a família ela é o maior empecilho! A família, ela não participa e muitas vezes é preciso o agente de saúde vir até o profissional pra tá chamando, porque a família é muita exclusa nisso aí e quando ela tá presente quer que a gente tome conta do paciente. Muitas vezes ela quer responsabilidade só da gente e acaba se eximindo da responsabilidade dela (profissional de saúde A).

Afirmam, também, que a maioria das famílias priva o esquizofrênico do convívio social e que a sociedade é preconceituosa, excluindo-o do seu meio. A família tem toda a sua rotina modificada a partir do diagnóstico, exigindo-se dela, nessa fase inicial da doença, uma dedicação quase exclusiva ao doente, por tratar-se de um período em que o quadro clínico passa pelas maiores oscilações.

[...] A família é omissa! A comunidade é rotulante! Pra comunidade todo mundo é doido e não esquizofrênico! [...] A família é omissa tanto no cuidado como na socialização do problema [...] (profissional de saúde F).

[...] A família quer esconder para procurar ajuda, mas quando é pra ter um auxílio-beneficio da previdência social eles logo mostram o paciente pelo dinheiro, mas quando é alguma coisa assim referente à ajuda para o paciente ter um acompanhamento de profissionais capacitados a família não quer levar não, eles preferem excluir o paciente. Essa é nossa realidade! (profissional de saúde G).

De fato, a família parece despreparada, mas não por vontade própria, são múltiplos os fatores que fazem com que ela não aceite a necessidade do tratamento do esquizofrênico. Muitas vezes a própria desinformação ocasiona isso, o que ocorre quando os familiares não compreendem o que vem a ser a esquizofrenia, suas principais manifestações e seus efeitos na vida do esquizofrênico (PALMEIRA; GERALDES; BEZERRA, 2009).

Aspectos como a negação da doença e a dificuldade em expressar seus sentimentos, o entendimento da esquizofrenia com o sentido de limitações, o cansaço e sobrecarga, com prejuízo da qualidade de vida, e incerteza em relação ao futuro são fatores que refletem nas dificulda-

Fractal, Rev. Psicol., v. 31 - n. 1, p. 2-10, 2019 des vivenciadas no cotidiano. Restando, por vezes, à família apenas a resiliência e a fé, como fonte de consolo e alívio (OLIVEIRA; FUREGATO, 2012).

São muitos os estigmas que a esquizofrenia causa à sociedade, e a família, muitas vezes por não querer ser vista de forma diferente pela condição de um de seus membros, acaba por não aceitar o diagnóstico e até mesmo querer suprimir a realidade. Em outros casos, quando aceitam o diagnóstico, os familiares acabam não compreendendo seu real significado e consideram a pessoa inválida para uma vida produtiva. Alguns profissionais, embora disponham de formação intelectual, acabam por confirmar as ideias dos familiares ao conceberem o sofrimento mental como invalidez e ao não ampliarem a compreensão que têm sobre as potencialidades da pessoa com esquizofrenia.

A ausência de ações e de atividades voltadas às pessoas com esquizofrenia na $\mathrm{AB}$ foi vista como outro entrave a ser enfrentado, implementando-se ações programadas realizadas pelas equipes, como visitas domiciliares, trabalho com grupos educativos, atendimento individual, entre outros, rompendo com o medo de lidar com este grupo:

O principal problema é que não existe uma ação programada para atender essas pessoas. Existe um estigma muito grande acerca da esquizofrenia que as pessoas têm até medo de se envolver numa situação dessa e por isso se torna complicado (profissional de saúde F).

[...] o maior problema está na estrutura da atenção básica hoje, onde não se há condições de desenvolver muitas dessas ações, porque isso necessita de um transporte adequado para os profissionais para fazerem essa visita, outro que é necessário que todos trabalhem juntos, coisa que não existe! (profissional de saúde J).

Através das falas, identifica-se a necessidade de se trabalhar o meio social no qual o usuário está inserido e ampliar a visão do processo saúde-doença mental, com vistas a intervir de modo a considerar todos seus aspectos biopsicossociais. Mencionou-se, também, a existência de problemas conjunturais dos serviços como empecilhos à efetivação de ações em saúde mental, uma vez que se torna difícil desenvolver a assistência preconizada pela Política Nacional devido à insuficiência de recursos materiais e estruturais nesta realidade.

Destacou-se, ainda, a dificuldade de articulação entre a atenção básica e os serviços especializados:

A falta de uma contrarreferência que deveria existir, pois o paciente não é acompanhado após 'dá 'inicio ao tratamento, uma vez que a demanda na atenção básica não deixa muito tempo pra realizar visitas domiciliares e 'dá' a atenção necessária a estes pacientes (profissional de Saúde A).

Outra problemática exposta pelos profissionais foi a contrarreferência ligada à falta de articulação na RAPS, com reflexo da grande demanda de atendimento na atenção básica, que impede que os profissionais tenham maior tempo para se dedicarem a usuários com este perfil. Mesmo existindo estratégias de intervenção de saúde mental na $\mathrm{AB}$, como o matriciamento, na prática falta maior en- 
gajamento entre os profissionais da rede e incentivo por parte da gestão local no que se refere a sua implantação no cotidiano dos serviços (JORGE et al., 2015).

O matriciamento em saúde na $\mathrm{AB}$ visa a uma atuação conjunta e qualificada entre as equipes da ESF, do Núcleo Ampliado de Saúde da Família na Atenção Básica (NASF-AB) ou mesmo da RAPS, como o CAPS, pois no geral dispõe de médico psiquiatra, psicólogo, terapeuta ocupacional, entre outros. Neste cenário, criam-se possibilidades para discussão e suporte clínico de casos, apoio na formulação do Projeto Terapêutico Individual ou mesmo a formulação de uma agenda de educação permanente entre os profissionais (JORGE et al., 2015).

Menciona-se que a efetivação da Política Nacional de Saúde Mental entre os municípios brasileiros é permeada por controvérsias e dificuldades, tendo em vista aspectos como a falta investimento da gestão das ações e serviços em nível local, falta de preparo e escassez de recursos humanos entre as equipes de profissionais, além da grande demanda de atividades cotidianas que envolvem o trabalho na $\mathrm{AB}$.

Circunscrevendo esse cenário, observa-se a dificuldade em incluir a família no tratamento, embora se identifique a necessidade de apoio e suporte a pessoa com esquizofrenia em suas redes de convívio, inclusive acerca das medidas necessárias para evitar os episódios de crise. Sabe-se que as reais dimensões da esquizofrenia têm implicações diretas para a pessoa que sofre com a doença e sua família (PALMEIRA; GERALDES; BEZERRA, 2009).

Em contraposição, houve profissionais que afirmaram:

Não! Não existe nenhum problema, porque quando há esse tipo de paciente o recebemos logo, dando prioridade pra ele. Aqui ele é bem atendido! Agora o acompanhamento mais seguro é o do CAPS! [...] Não há nenhum proble$m a$, não, porque aqui na unidade tem de tudo o que eles precisam! (profissional de saúde C).

[...] em relação a esses pacientes, não temos nem tantas dificuldades, não, porque, assim... Principalmente quando ele precisa de medicamento que a prescrição só é feita pelo médico com um receituário controlado, mas a gente tenta agilizar para que eles não fiquem sem medicamento [...] (profissional de saúde G).

Os depoimentos expressam certa limitação em relação à compreensão das necessidades do usuário do serviço, do ponto de vista das políticas públicas de saúde mental, mencionando apenas a transcrição das receitas médicas feitas pelo médico psiquiatra e visitas domiciliares esporádicas. Eles frisaram, em muitos momentos, os aspectos biológicos da doença, ou não os associaram aos outros fatores determinantes do quadro clínico dos usuários, o que acaba por conceber uma definição equivocada das estratégias utilizadas para prestar assistência a essa clientela.

Furtado (FURTADO; CAMPOS, 2005) aponta que, antes de tudo, a pessoa com transtorno mental necessita de vínculo, escuta e acolhimento por parte dos profissionais que compõem a $\mathrm{AB}$, de maneira a valorizar suas demandas e sua singularidade enquanto sujeito capaz de conviver em sociedade. Compreende-se que, além do acesso a medicamentos e a consultas médicas, importan- tes no tratamento, torna-se fundamental fortalecer a autonomia do usuário, seus modos de viver e se relacionar com o outro, valorizar suas potencialidades, suas relações de afeto e estima na comunidade.

\section{Possibilidades para melhoria do trabalho em saúde mental}

Apreenderam-se estratégias fundamentais para a melhoria do trabalho em saúde mental no âmbito da $\mathrm{AB}$, a partir da visão dos profissionais. A primeira estratégia mencionada foi fortalecer o processo de educação permanente dos profissionais e, por conseguinte, melhorar a qualidade da assistência:

Pelo que conheço, só é possível superar parcialmente algumas dificuldades a partir do trabalho conjunto entre a equipe de saúde, pela busca do conhecimento por parte do profissional que precisa se capacitar para atender estes pacientes que apresentam muitas especificidades. Só assim que é possivel melhorar a qualidade da assistência presta$d a !$ (profissional de saúde B).

Olha, o que eu faço é estudar psiquiatria para poder diagnosticar o paciente [...] poder dar o diagnóstico inicial para poder referenciar o paciente para que ele chegue no especialista. A Unidade Básica de Saúde eu acho que ela só 'tá preparada para diagnosticar, tirar o paciente da fase crítica, quando dentro do possível, e referenciar para diminuir o risco desse paciente (profissional de saúde C).

As falas confirmam o esforço individual por parte de alguns profissionais em aprimorar seus conhecimentos, com vistas a oferecer uma melhor conduta ou intervenção terapêutica às situações que chegam à unidade básica de saúde. Assim, evidencia-se a necessidade de se ampliar esse processo de qualificação em saúde mental às equipes da $\mathrm{AB}$ mediante a implementação do processo de educação permanente. Reconhece-se que a discussão conjunta de casos clínicos, implantação de cursos de formação e capacitação, formação de grupos de estudos, entre outros, constituem estratégias que potencializam o trabalho interdisciplinar, fortalecem a RAPS e impactam a qualidade da assistência ofertada.

No Brasil, a Política de Educação Permanente em Saúde (PNPS) aponta a necessidade de melhorar as ações e serviços de saúde, por meio da formação e qualificação das equipes de profissionais em um processo dinâmico e integrador, capaz de estimular o desenvolvimento individual e coletivo dos envolvidos.

Outro aspecto estratégico apontado pelos profissionais refere-se a qualificar e estimular a participação da família no tratamento:

\footnotetext{
A família não está preparada, não tem conhecimento sobre a doença, então você tem que trabalhar a família, conscientizar ela do que é a doença do paciente e como ela deve reagir às alterações de comportamento do paciente e entender $o$ que se passa, também para ela começar a perceber as alterações e nunca deixar o paciente sem o tratamento adequado de modo a sempre procurar o especialista, sempre procurar o médico para encaminhar [...] (profissional de saúde D).

[...] A implementação da participação da família e da comunidade para dar atenção ao paciente psiquiátrico é
} 
educação, esclarecer o que é a doença e saber entender o paciente, o que é que ele está sentindo, porque é que ele está sentindo aquilo (profissional de saúde D).

A família, ao lidar com a doença mental, nem sempre se mostra de fato preparada. Faltam informação acerca dos sintomas e maior capacidade de ação frente às diversas situações e à nova realidade do lar. No geral, visualiza-se uma postura de omissão dos serviços de saúde, especialmente na abordagem a esse público, ou mesmo o sentimento de culpabilização da família pela situação vivida, todavia, poucas estratégias capazes de fortalecer a participação ativa dos familiares nos serviços de atenção básica vêm sendo implementadas.

Observa-se que a participação da família no tratamento em saúde mental ainda constitui um desafio para os profissionais e serviços, fato que se reflete diretamente no processo de exclusão e rejeição da pessoa com esquizofrenia da vida em comunidade.

[...] É muito complicado porque ninguém se aproxima dessa pessoa e ela não vai ter um cuidado e assim ela vai se sentir rejeitada e não vai buscar esse cuidado. Vai se sentir doido realmente! Numa crise ele vai pra um hospital psiquiátrico de onde ele volta pior do que ele foi, que geralmente é isso que acontece. Então esse é o fator complicador. A comunidade rotula e a família esconde o caso dentro de casa [...] (profissional de saúde F).

[...] tem família que não liga, que os paciente são largados, vivem trancados, a higiene é precária. E outros não! Que cuidam bem dos pacientes, que já são bem tratados, que participam de terapias no CAPS, na APAE, depende muito. Isso é muito relativo. Depende muito de família pra família, umas incluem e outras excluem (profissional de saúde I).

As falas expressam a responsabilização da família pelo cuidado com este grupo de usuários que supervalorizam as limitações impostas pela doença e minimizam suas potencialidades, contribuindo para o estigma e o preconceito por parte da sociedade. Apesar da maior homogeneidade, para alguns profissionais não é possível estabelecer uma verdade absoluta em relação a esse ponto, pois, segundo eles, isso é uma coisa que varia conforme a estrutura familiar.

Diante dos entraves apontados, os participantes do estudo identificaram ainda outros instrumentos de intervenção a serem potencializados na $\mathrm{AB}$, como a visita domiciliar, que possibilita uma aproximação entre família, usuário e serviço no processo formação de vínculo que ajude na adesão da terapêutica. A visita domiciliar parece estar sendo a única alternativa de dinamização do trabalho e pela busca pelo conhecimento em psiquiatria, especificamente em esquizofrenia.

Franco (2003) defende a resolutividade na rede básica vinculada ao recurso instrumental, conhecimento técnico dos profissionais, ação acolhedora, vínculo e a relação profissional/usuário. Entretanto, na realidade da $\mathrm{AB}$ se percebe a ausência de ações coletivas voltadas às pessoas com transtornos mentais e atividades capazes de

Fractal, Rev. Psicol., v. 31 - n. 1, p. 2-10, 2019 promover espaços de interação entre os grupos, não se limitando ao ato de medicar, a visita domiciliar ou mesmo encaminhar para o serviço de referência.

Para a garantia da assistência integral e humanizada na rede de saúde mental, conforme preconiza a reforma psiquiátrica, existe a necessidade de suporte financeiro à rede dos serviços comunitários em saúde e sistematização do processo de trabalho, e para tanto é fundamental conhecer as necessidades dos cuidadores e das famílias e traçar estratégias para a resolução dessas demandas (BESSA; WAIDMAN, 2013).

A respeito da busca por mudanças no quadro atual das ações em saúde mental, Silveira, D. (2003) destaca a necessidade de unir esforços, sejam dos profissionais, das famílias ou da sociedade, em prol de uma assistência qualificada que atenda às necessidades da pessoa com transtorno mental. Menciona, ainda, que a gestão e os profissionais de saúde necessitam conhecer e efetivar os princípios da Política Nacional, propiciando meios e recursos que aproximem as ações em saúde mental no cotidiano da AB.

\section{Considerações finais}

A partir do conhecimento sobre o desenvolvimento da assistência à pessoa com esquizofrenia na atenção básica, evidenciou-se que ele ocorre de uma forma que não possibilita identificar as maiores necessidades dessa clientela e distante da garantia do princípio da integralidade. As ações para a promoção da saúde da pessoa que sofre de esquizofrenia são desenvolvidas a partir de um trabalho desarticulado com o serviço de saúde em questão, de forma fragmentada, seguindo um modelo ambulatorial e programático, em que cada profissional desenvolve o seu trabalho sem manter grandes elos de comunicação.

Nesse modelo de atendimento, baseado na lógica do encaminhamento sem contrarreferência e na supervalorização da consulta médica e do uso da medicação, tanto a família como a sociedade parecem ser excluídas dos planos de intervenção, o que caracteriza uma noção reducionista de abordagem em saúde, que enxerga apenas o usuário do serviço de saúde e desconsidera o meio no qual está inserido.

O trabalho desenvolvido na atenção básica mostrou-se totalmente dependente do que é desempenhado no CAPS, no setor hospitalar psiquiátrico e no setor privado, ao passo que apenas repete parte do que é feito no serviço especializado. A dependência existente não significa necessariamente vinculação dos profissionais da ESF à referência, mas sim baixa autonomia nas intervenções.

Acredita-se que a realidade poderia ser alterada através da qualificação permanente dos profissionais da atenção básica, da efetivação de um sistema de referência e contrarreferência entre atenção básica e serviço especializado, da efetivação das políticas públicas em saúde mental, da promoção de recursos por parte da iniciativa pública para desenvolver estas ações e da diversificação de instrumentos de intervenção que expandam as ações para a comunidade. 
Compreende-se que apenas a partir da efetiva apreensão da realidade como um todo e do compromisso com a melhoria da qualidade dos serviços oferecidos pela atenção básica é que se tornará possível trilhar os caminhos para a construção de ações em saúde integrais, comprometidas, sobretudo, com a promoção da saúde que se envolve com a melhoria das dimensões sociais do esquizofrênico.

\section{Referências}

ASSOCIAÇÃO BRASILEIRA DE PSIQUIATRIA. Diretrizes para um modelo de assistência integral em saúde mental no Brasil. Rio de Janeiro: ABP, 2014. Disponível em: http://www. abpbrasil.org.br/diretrizes_final.pdf. Acesso em: 23 maio 2016.

BESSA, Jacqueline Botura; WAIDMAN, Maria Angélica Pagliarini. Família da pessoa com transtorno mental e suas necessidades na assistência psiquiátrica. Texto \& Contexto em Enfermagem, Florianópolis, v. 22, n. 1, p. 61-70, 2013. Cross ${ }^{\text {Ref }}$

BRASIL. Presidência da República. Casa Civil. Subchefia para Assuntos Jurídicos. Lei $n^{\circ} 10.216$, de 6 de abril de 2001. Dispõe sobre a proteção e os direitos das pessoas portadoras de transtornos mentais e redireciona o modelo assistencial em saúde mental. 2001. Disponível em: http:/www.planalto.gov. br/ccivil_03/LEIS/LEIS_2001/L10216.htm. Acesso em: 22 jul. 2016.

BRASIL. Ministério da Saúde. Secretaria de Atenção à Saúde. Departamento de Ações Programáticas Estratégicas. Saúde mental no SUS: os centros de atenção psicossocial. Brasília: Ministério da Saúde, 2004. Disponível em: http://www.ccs. saude.gov.br/saude_mental/pdf/sm_sus.pdf. Acesso em: 18 out. 2016.

BRASIL. Ministério da Saúde. Saúde Mental em Dados 12, ano 10, n. 12. Informativo eletrônico. Brasília, out. 2015. Disponível em: http://www.mhinnovation.net/sites/default/ files/downloads/innovation/reports/Report_12-edicao-doSaude-Mental-em-Dados.pdf. Acesso em: 18 jun. 2016.

CANABRAVA, Danielly de Souza et al. Tratamento em saúde mental: estudo documental da legislação federal do surgimento do Brasil até 1934. Rev. Eletr. Enf., Goiás, v. 12, n. 1, p. 170176, 2010. Disponível em: https://www.fen.ufg.br/revista/v12/ n1/pdf/v12n1a21.pdf. Acesso em: 22 maio 2016.

FERREIRA, Fernanda Nunes et al. Avaliação das atitudes de estudantes da área da saúde em relação a pacientes esquizofrênicos. Rev. bras. educ. med., Rio de Janeiro, v. 39, n. 4, p. 542-549, 2015. Cross ${ }^{\text {Ref. }}$

FERREIRA, Gina. A reforma psiquiátrica no Brasil: uma análise sócio política. Revista de Psicanálise, v. 4, n. 1, p. 7785, 2006. Disponível em: https://www.ebah.com.br/content/ ABAAAfH-IAH/a-reforma-psiquiatrica-no-brasil-analisesocio-politica. Acesso em: 3 maio 2016.

FRANCO, Túlio Batista. Integralidade na assistência à saúde: a organização das linhas de cuidado. São Paulo: Hucitec, 2003.

FURTADO, Juarez Pereira; CAMPOS, Rosana Teresa Onocko. A transposição das políticas de saúde mental no Brasil para a prática nos novos serviços. Rev. latinoam. psicopatol. fundam., São Paulo, v. 8, n. 1, p. 109-122, jan./mar. 2005. Cross ${ }^{\text {Ref }}$

HANSEN, Nayara Fernanda et al. A sobrecarga de cuidadores de pacientes com esquizofrenia: uma revisão integrativa da literatura. Revista Eletrônica de Enfermagem, Goiás, v. 16, n. 1, p. 220-227, 2014. Disponível em: https://www.fen.ufg.br/ revista/v16/n1/pdf/v16n1a25.pdf. Acesso em: 28 nov. 2018.
HENGARTNER, Michael Pascal et al. Atitudes de profissionais de saúde mental em relação a indivíduos com esquizofrenia: uma comparação transcultural entre Suíça e Brasil. Rev. psiquiatr. clín., São Paulo, v. 39, n. 4, p. 115-121, 2012. Cross ${ }^{\text {Ref }}$

JARDIM, Katia; DIMENSTEIN, Magda. Risco e crise: pensando os pilares da urgência psiquiátrica. Psicologia em Revista, Belo Horizonte, v. 13, n. 1, p. 169-190, 2007. Disponível em: http://periodicos.pucminas.br/index.php/ psicologiaemrevista/article/view/267/276. Acesso em: 21 nov. 2018.

JORGE, Maria Salete Bessa et al. Apoio matricial, projeto terapêutico singular e produção do cuidado em saúde mental. Texto \& Contexto em Enfermagem, Florianópolis, v. 24, n. 1, p. 112-120, 2015. Cross ${ }^{\mathrm{Ref}}$

LOCH, Alexandre Andrade et al . O estigma atribuído pelos psiquiatras aos indivíduos com esquizofrenia. Rev. psiquiatr. clín., São Paulo, v. 38, n. 5, p. 173-177, 2011. Cross ${ }^{\text {Ref }}$

MINAYO, Maria Cecília de Souza. et al. Pesquisa Social: teoria, método e criatividade. 21 ed. Petrópolis, RJ: Vozes, 2002. Disponível em: https://wp.ufpel.edu.br/franciscovargas/ files/2012/11/pesquisa-social.pdf. Acesso em: 21 nov. 2018.

OLIVEIRA, Renata Marques de; FUREGATO, Antonia Regina Ferreira. Um casal de idosos e sua longa convivência com quatro filhos esquizofrênicos. Rev. esc. enferm. USP, São Paulo, v. 46, n. 3, p. 618-625, 2012. Cross ${ }^{\text {Ref }}$

PALMEIRA, Leonardo Figueiredo; GERALDES, Maria Thereza de Moraes; BEZERRA; Ana Beatriz Costa. Entendendo a esquizofrenia: como a família pode ajudar no tratamento? Rio de Janeiro: Interciência, 2009.

PESSOA JÚNIOR, João Mário et al. A política de saúde mental no contexto do hospital psiquiátrico: desafios e perspectivas. Escola Anna Nery, Rio de Janeiro, v. 20, n. 1, p. 83-99, 2016. Disponível em: http://www.scielo.br/scielo.php?script=sci arttext\&pid=S1414-81452016000100083. Acesso em: 25 maio 2016.

SHIRAKAWA, Itiro. Aspectos gerais do manejo do tratamento de pacientes com esquizofrenia. Rev. Bras. Psiquiatr., São Paulo, v. 22, supl. 1, p. 56-58, 2000. Cross ${ }^{\text {Ref }}$

SILVA, Carlos Magno Carvalho da Silva et al. Visita domiciliar na atenção à saúde mental. Cienc. enferm., Concepción, v. 17, n. 3, p. 125-136, 2011. Cross ${ }^{\text {Ref }}$

SILVEIRA, Daniele Pinto da. Sofrimento psíquico e serviços de saúde: cartografia da produção do cuidado em saúde mental na atenção básica de saúde. Rio de Janeiro: s. n., 2003. Disponível em: http://teses.icict.fiocruz.br/pdf/silveiradpm.pdf. Acesso em: 27 maio 2016.

SILVEIRA, Lia Carneiro; BRAGA, Violante Augusta Batista. Acerca do conceito de loucura e seus reflexos na assistência de saúde mental. Rev. Latino-Am. Enfermagem, Ribeirão Preto, v. 13, n. 4, p. 591-595, jul./ago. 2005. Disponível em: http:// www.scielo.br/scielo.php?script=sci_arttext\&pid=S010411692005000400019\&lng=en\&nrm=iso. Acessado em: 27 maio 2016.

Recebido em: 12 de agosto de 2016 Aceito em: 13 de dezembro de 2018

Fractal, Rev. Psicol., v. 31 - n. 1, p. 2-10, 2019 